Article

\title{
Expansion of Industrial Plantations Continues to Threaten Malayan Tiger Habitat
}

\author{
Varada S. Shevade ${ }^{1, *}$, Peter V. Potapov ${ }^{1}$, Nancy L. Harris ${ }^{2}$ and Tatiana V. Loboda ${ }^{1}$ \\ 1 Department of Geographical Sciences, University of Maryland, College Park, MD 20742, USA; \\ potapov@umd.edu (P.V.P.); loboda@umd.edu (T.V.L.) \\ 2 World Resources Institute, 10 G Street NE Suite 800, Washington, DC 20002, USA; nharris@wri.org \\ * Correspondence: vshevade@terpmail.umd.edu
}

Received: 28 May 2017; Accepted: 5 July 2017; Published: 19 July 2017

\begin{abstract}
Southeast Asia has some of the highest deforestation rates globally, with Malaysia being identified as a deforestation hotspot. The Malayan tiger, a critically endangered subspecies of the tiger endemic to Peninsular Malaysia, is threatened by habitat loss and fragmentation. In this study, we estimate the natural forest loss and conversion to plantations in Peninsular Malaysia and specifically in its tiger habitat between 1988 and 2012 using the Landsat data archive. We estimate a total loss of 1.35 Mha of natural forest area within Peninsular Malaysia over the entire study period, with 0.83 Mha lost within the tiger habitat. Nearly half $(48 \%)$ of the natural forest loss area represents conversion to tree plantations. The annual area of new plantation establishment from natural forest conversion

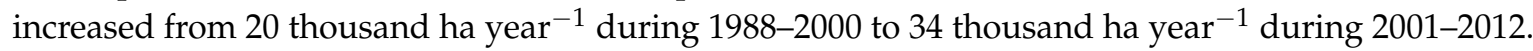
Large-scale industrial plantations, primarily those of oil palm, as well as recently cleared land, constitute $80 \%$ of forest converted to plantations since 1988 . We conclude that industrial plantation expansion has been a persistent threat to natural forests within the Malayan tiger habitat. Expanding oil palm plantations dominate forest conversions while those for rubber are an emerging threat.
\end{abstract}

Keywords: Peninsular Malaysia; tiger habitat; forest loss; plantations; oil palm; rubber

\section{Introduction}

Malaysia is a megadiverse country [1] and is a part of the Southeast Asian biodiversity hotspot [2]. The Malayan tiger, Panthera tigris jacksoni, is endemic to Peninsular Malaysia and is threatened by habitat loss, in addition to poaching and the illegal trade of tiger parts, hunting of tiger prey, and retaliatory killings arising from human-wildlife conflicts [3]. Following recent reports of a decline in Peninsular Malaysia's tiger population, the Malayan tiger is now classified by the International Union for Conservation of Nature (IUCN) as a critically endangered species, i.e., a species facing an extremely high risk of extinction in the wild [3]. Current estimates suggest a likely population of 250-340 adult tigers and an effective breeding population of $80-120$ tigers, indicating a greater than $25 \%$ decline in one generation (equivalent to seven years) [3]. Additionally, repeated population studies at a couple of sites indicate a 50 and $90 \%$ decline in tiger density estimates [3].

Increasing human population, in addition to agricultural and infrastructure development, have resulted in the reduction of wildland extent, forcing tigers to survive in human-dominated landscapes [4]. Asian countries have the highest population densities in forested areas and a long history of agricultural development [5]. Southeast Asia has some of the highest deforestation rates globally [6] and has a large proportion of cultivated/agricultural land under tree plantations [5]. Peninsular Malaysia has a long history of land cover and land use change. Expanding agriculture, especially rubber (Hevea brasiliensis) and oil palm (Elaeis guineensis) plantations, has been historically responsible for forest reduction in the region [7-10]. Rubber plantations in Peninsular Malaysia first appeared in the 1880s [11] and expanded rapidly after a surge in rubber prices during 1905-1910 [12]. 
Oil palm plantations appeared in Malaysia as early as 1917 [13] and with a drop in rubber prices in the 1960s, commercial oil palm plantations started replacing those of rubber [12]. By the 1940s, Peninsular Malaysia's west coastal region was already heavily deforested. It had lost half of its original forest area by the late 1980s, while agricultural land had expanded from an estimated 21 to $35 \%$ of the land area between 1966 and 1982 [14]. Agricultural expansion and oil palm production are considered significant threats to biodiversity and tiger habitat in Peninsular Malaysia [6,15].

Historically, tigers inhabited all forest areas of Peninsular Malaysia [16]. Currently, most breeding tiger populations are restricted to protected areas due to intensive human pressure [17]. Rapidly growing economies and expanding markets have put greater pressure on the remaining tiger habitats [4]. As a commitment to doubling wild tiger numbers by 2022, tiger-range countries adopted the Global Tiger Recovery Program (GTRP) [18]. Under the GTRP, Malaysia's National Tiger Recovery Program (NTRP) will focus on its National Tiger Recovery Priorities and the tiger recovery strategy described in its National Tiger Conservation Action Plan (NTCAP) [19], which has identified the 'net loss and gain of forests' as an indicator for monitoring conservation actions, along with other indicators like tiger occupancy (presence or absence of species at sites within the study area), prey and tiger densities, and the use of corridors by tigers [20]. While collecting data for most of these indicators is costly and time consuming, monitoring habitats using remotely sensed data may be achieved with minimal investments. Remote sensing is an effective tool for change assessment and the repeatable monitoring of large and remote tracts of land. Various remotely sensed datasets have been specifically generated to estimate the spatial extent of forest cover and forest loss from regional to global scales [21-25]. Landsat's $30 \mathrm{~m}$ spatial resolution allows mapping at a scale congruent with most human activity [25]. The Landsat program also features the longest data archive suitable for multi-decadal regional change assessments [26]. Remotely sensed forest and forest change products often use a biophysical forest definition, which includes forestry dynamics and plantation cycles in the quantification of forest and forest loss area [24,27]. Natural forests and tree plantations offer a different suitability as tiger habitats. Plantations, like those of oil palm, have a uniform tree-age structure [13], support fewer species than primary, logged, or disturbed forests [13,28], or even degraded forests [29], and provide poor habitat for tigers [30]. Additionally, agricultural expansion also impacts tigers through access for poaching, disruption of connectivity for movement and dispersal, and by increasing human-tiger conflicts [15]. Hence, it is important to separate natural forests from plantations when assessing forest dynamics in the context of tiger habitat.

Some studies providing forest loss estimates for Malaysia [10,31] use national land use data compiled by the Food and Agriculture Organization of the United Nations (FAO) or other sources and do not distinguish between Peninsular Malaysia and Malaysian Borneo, which have very different land cover and land use change dynamics. This is partly due to the autonomy of states to make land and forest resource decisions [15,32]. Previous studies providing forest loss estimates for Peninsular Malaysia [23,33] do not focus on tiger habitat and only a recent study by [17] assessed forest loss within the global priority tiger conservation landscapes (TCLs) across all tiger-range countries, identifying Malaysia's Taman-Negara-Belum as a TCL with some of the highest forest loss during 2001-2014.

Given the history of land cover changes in Peninsular Malaysia and the role of plantations in land use conversion, it is important to assess the drivers of forest loss in the region and to quantify the role of plantation expansion. In this study, we assess recent forest dynamics in Peninsular Malaysia and considering the Malayan tiger as an example of Malaysia's endangered and threatened megafauna, we specifically focus on forest dynamics within Malaysia's tiger landscapes. The overarching goal for this study was to quantify the area of natural forest loss and conversion to plantations between 1988 and 2012 within Malaysia's tiger habitat. The specific objectives of this study were: (1) to map Peninsular Malaysia's natural forest in 1988 as a proxy for potential tiger habitat; (2) map and quantify natural forest loss between 1988 and 2012 in Peninsular Malaysia and its tiger habitat; and (3) quantify the proportion of the total forest and tiger habitat loss converted to plantations. 


\section{Materials and Methods}

\subsection{Study Area}

Peninsular Malaysia lies on the Malay Peninsula and is bordered by Thailand in the North and Singapore in the South. It occupies an area of 13.2 million ha (Figure 1). The region is equatorial with influences of the southwest monsoon from May to September and the northeast monsoon from October to March. Average day temperatures are around $32{ }^{\circ} \mathrm{C}$ and average precipitation is around $2550 \mathrm{~mm}$ with a maximum rainfall of more than $5000 \mathrm{~mm}$ on exposed mountains [34]. Coastal plains and lowlands dominate regional topography below a $300 \mathrm{~m}$ elevation [34], which are covered with mangroves and peat swamp forests along the coast and lowland dipterocarp forests further inland [35]. Mountain ranges dominate the northern and central-western parts of the country [34]. Hill and upper dipterocarp forests are found between 300-750 m and 750-1200 m above sea level, respectively, while montane-oak forests are found between 1200-1500 m [35]. About 51\% of Peninsular Malaysia has a suitable habitat for tigers; however, only $29 \%$ of its area is considered to have good conservation value based on evidence of tiger presence [20]. Protected areas represent only 15\% of the tiger habitat area [20]. Tiger habitat for the purpose of this study is restricted to Peninsular Malaysia's Tiger Conservation Landscapes (TCLs) (Figure 1), which include areas with a potential effective habitat and confirmed tiger occurrence during the preceding years and no knowledge of tiger extirpation [36].

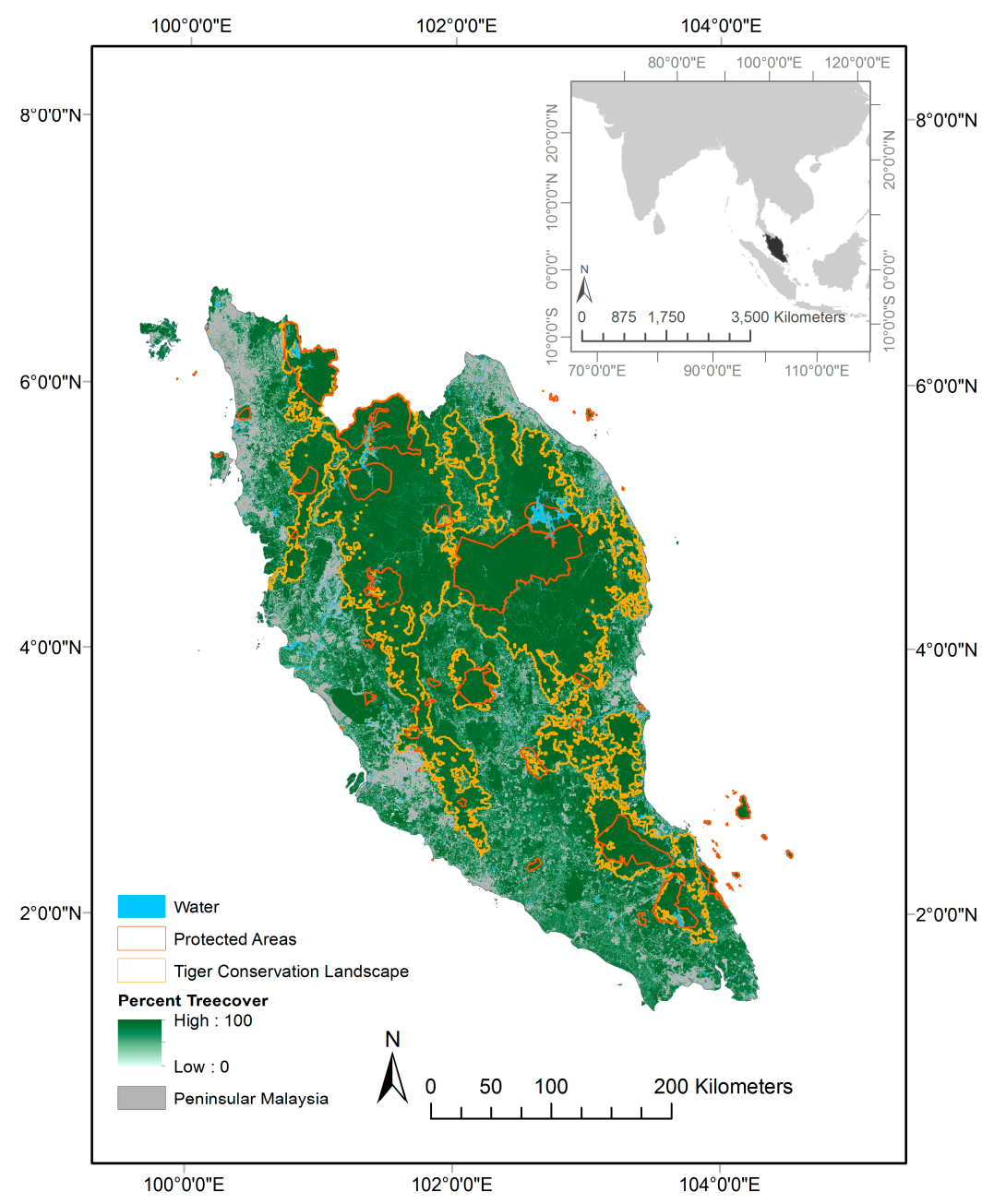

Figure 1. Study area in Peninsular Malaysia showing the Tiger Conservation Landscapes (TCL) [36], percent tree cover for year 2000 [24], and protected areas from the World Database on Protected Areas (WDPA) [37]. 


\subsection{Overview}

Natural forests are defined as mature naturally regenerated forests that have a minimum area of $5 \mathrm{ha}$, and have not been completely cleared or replanted in recent history, although some signs of disturbance like selective logging might be present [27]. Natural forest loss includes tree removal due to logging, as well as land use conversion (from agriculture and plantation expansion, infrastructure development, etc.). To quantify natural forest loss, we: (1) mapped the natural forest extent for the year 1988; (2) applied a change detection model to map forest loss between 1988 and 2000; and (3) aggregated the pre-year 2000 forest loss with the existing published Landsat-based Global Forest Change (GFC) tree cover loss product for 2001-2012 [24] and assessed the loss within mapped natural forests (Figure 2). We then overlaid the plantation map obtained from [38] with the 1988-2012 natural forest loss map to estimate the role of plantations in the overall forest loss. PCI Geomatica software was used for generating training samples for natural forest and forest loss mapping, while ArcGIS was used for the analysis of forest loss and conversion to plantations.

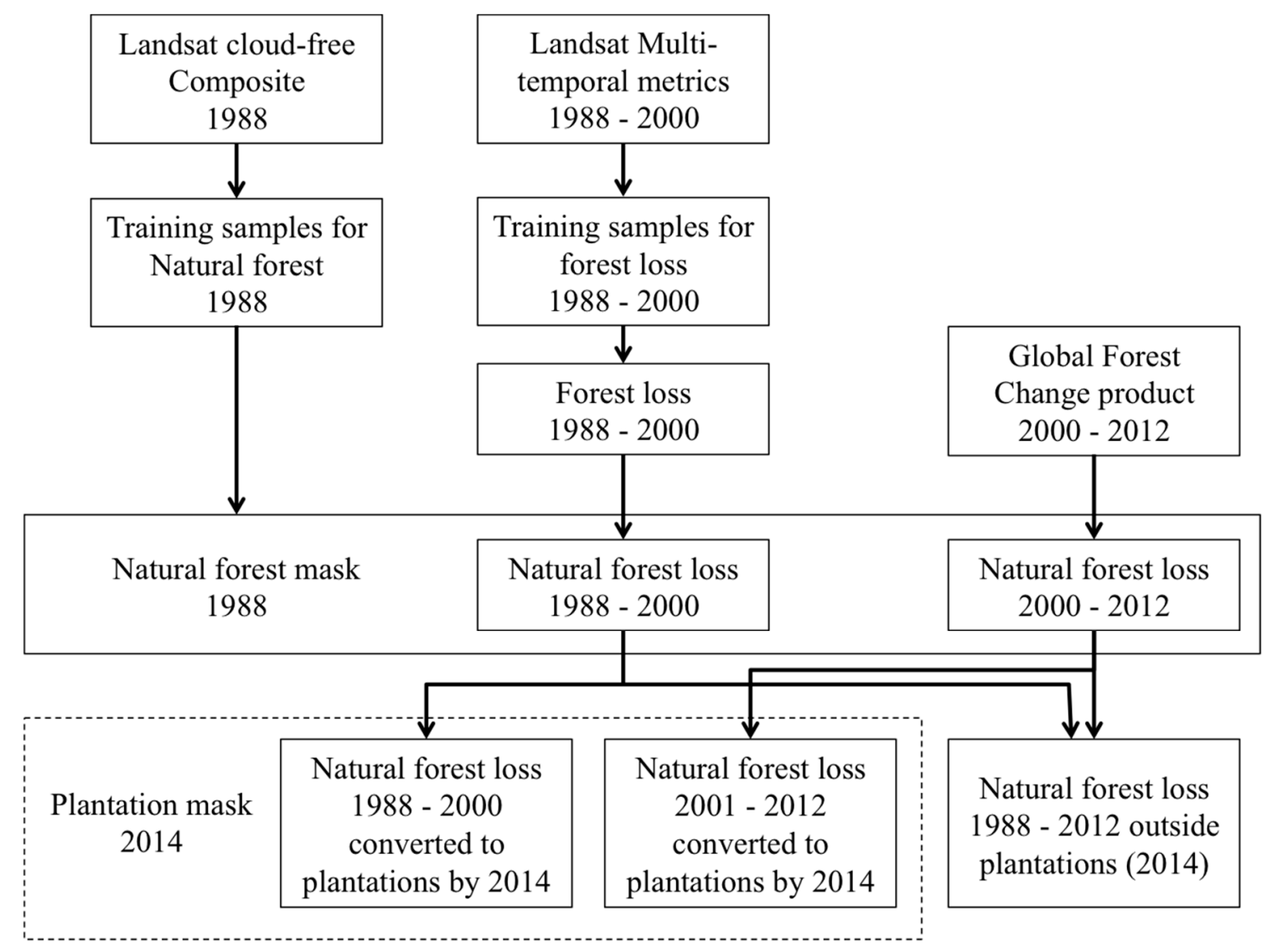

Figure 2. Methodology used to map natural forest, natural forest loss, and plantation expansion.

\subsection{Data}

We analyzed the entire archive of Landsat 5 Thematic Mapper (TM) and Landsat 7 Enhanced Thematic Mapper (ETM+) images available for the region from 1988 to 2002. The region is covered by 20 WRS-2 footprints. The entire archive of available imagery, consisting of 1110 processing Level 1 terrain corrected (L1T) images was employed. The number of images used from the different Landsat sensors is listed in Table S1. Landsat imagery processing followed the methodology of [24] and is described in detail in [39], where per-pixel raw digital numbers were converted to top of atmosphere reflectance, screened for cloud/shadow/haze/water, and following quality assessment, were radiometrically normalized and composited into a single clear-surface layer. Screening and 
quality assessment involved using decision tree models to predict the presence of cloud, shadow, and water to obtain the per-pixel probability of contamination by these features [24,39]. The observation quality of pixels was recorded and pixels with a high probability of contamination were then excluded from processing [24,39]. Normalization was carried out using Moderate Resolution Imaging Spectroradiometer (MODIS) derived surface reflectance products as normalization targets in order to reduce the variations in reflectance resulting from differences in image dates, atmospheric conditions, and surface anisotropy [39]. As Peninsular Malaysia is a part of the humid tropics, images from the entire year were used for multi-date image compositing in order to generate start or end date (1988 or 2000) cloud-free image mosaics using only pixels with the highest quality observations [39]. Due to limited image availability and the very high incidence of cloud cover in this region, clear surface observations from adjacent years were used to fill the gaps in both the image composites. For the "circa 1988" composite, $71 \%$ of the pixels used were from the 1988-1990 interval and for the "circa $2000 "$ " composite, $99 \%$ of the pixels used were from the 1999-2001 interval.

All processed per-pixel cloud-free observations between the earliest observation for the start year (1988) and the latest observation for the last year (2000) were used to create a set of multi-temporal metrics that was used for natural forest mapping and forest loss detection (Table 1). This multi-temporal metric set was developed following the methods described in $[24,39,40]$ using two approaches: (1) time-sequential reflectance observations by date; and (2) ranked (low to high) band reflectance values, or ranked observations corresponding to the ranked normalized difference vegetation index (NDVI) [41], normalized difference water index (NDWI) [42] values, and thermal/infrared band values. In addition to the start/end date cloud-free image mosaics, the means and medians of the first three observations and last three observations, the maximal values of time-sequential reflectance gain and loss, and the slope of linear regression of reflectance/index values and observation date $[24,40]$ were generated. For the rank-based metrics, a set of percentile values and symmetrical and asymmetrical averages for various percentile range intervals were used [24,40]. On average, about 16 cloud-free observations were available per-pixel for the calculation of metrics. The first (circa 1988) and last (circa 2000) cloud-free image composites, along with the medians/means of the first three and last three observations, were used for visual interpretation to generate training samples for mapping.

Table 1. Overview of the different multi-temporal metrics used for classification and mapping.

\begin{tabular}{ll}
\hline Types of Metrics & Multi-Temporal Metrics \\
\hline \multirow{2}{*}{ Image Composites } & 1. First and last cloud-free observations \\
& 2. Mean and Median of first 3 observations \\
& 3. Mean and Median of last 3 observations \\
\hline \multirow{3}{*}{ Rank-based Metrics } & 1. Percentiles representing minimum, $10 \%, 25 \%, 50 \%, 75 \%, 90 \%$ and maximum for band \\
& reflectance or index (NDVI, NDWI) values \\
& 2. Symmetrical averages for various intervals: minimum-maximum, 10-90\%, 25-75\% \\
& 3. Asymmetrical averages for various intervals: minimum-10\%, 10-25\%, 25-50\%, 50-75\%, \\
& 75-90\%, $90 \%$-maximum \\
\hline \multirow{2}{*}{ Trend Analysis Metrics } & 1. Slope of linear regression of band reflectance versus image date \\
& 2. Standard deviation of band reflectance $1988-2000$ \\
& 3. Maximum loss/gain of reflectance/index value between consecutive observations
\end{tabular}

We used the GFC tree cover loss product [24] for the years 2001-2012 to extend our 1988-2000 forest loss map. This product maps the loss of tree cover taller than $5 \mathrm{~m}$ at a resolution equivalent to Landsat data. To estimate forest loss converted to plantations, we used a plantation map generated for Peninsular Malaysia by the World Resources Institute (WRI) [38]. This product maps plantation areas in 2014, categorized into large industrial-sized plantations, medium-sized and small-sized mosaic plantations, and recently cleared or young plantation classes. Large industrial plantations are monocultures with species information associated with plantation areas, while mosaic plantations include some non-plantation areas like other agriculture, forest patches, and settlements interspersed with plantations. 


\subsection{Natural Forest Mapping}

The 1988 Landsat image mosaic was visually interpreted to determine the training samples for natural forest (dependent variable) versus all other land cover types. The natural forest classification training sample consisted of more than 450,000 training pixels. Multi-temporal metrics (Table 1) were used as independent variables to build a bagged decision tree model to map natural forest areas [24]. While using "bagging" or bootstrap aggregation, the data are divided into a test set, which is a random sample drawn from the training population, and a learning set, which is the remaining portion of the training population [43]. We used a test set of $20 \%$ of the training data and developed output maps based on the median class likelihood from the outputs of several trees.

Natural forest patch size was restricted to 5 ha [27] and manual editing of the classification results was performed [27] to correct for obvious errors, like removing older plantations and including some omitted water-logged forest areas along the coast. For this study, tiger habitat for Peninsular Malaysia is defined as natural forest area within the TCL. Tiger habitat and habitat are used interchangeably in the rest of the paper.

\subsection{Forest Loss Mapping}

Forest loss is defined as a temporal or permanent reduction in tree cover density $[24,27,44]$, resulting in a complete or almost complete removal of trees within a $30 \mathrm{~m}$ Landsat pixel [40]. It could result from conversion to agriculture/plantations, intensive logging, or natural disturbances. Training samples for 'forest loss' and 'no loss' between 1988 and 2000 were created after the visual interpretation of 1988 and 2000 image mosaics and maximum reflectance composites [40]. In total, more than 510,000 pixels were used to train the forest loss classification. Forest loss during 1988-2000 (pre-2000) was mapped in one time-step using a decision tree classifier and multi-temporal metrics. Forest loss during 2001-2012 (post-2000) within mapped natural forest areas was extracted from the GFC product. Owing to the increased image availability after the year 2000, as opposed to that in the 1980s and 1990s, we can estimate post-2000 loss at an annual time-step using the GFC product. All forest loss within the mapped 1988 natural forest mask was considered as natural forest loss (Figure 2). As the pre-2000 and post-2000 forest loss is mapped separately, in cases of overlap between the two, the loss year (interval) was attributed to the first detected loss event (pre-2000). However, as imagery from years 2001 and 2002 had been used to gap-fill the 2000 mosaic, in instances of overlap between mapped pre-2000 loss and the GFC product loss from either year 2001 or 2002, we attributed loss to the respective post-2000 year. Tiger habitat loss was quantified by assessing forest loss within the tiger habitat area.

\subsection{Sample-Based Adjustment of the Area Estimation}

Separate sample-based assessments were performed for the newly developed pre-2000 forest loss and the post-2000 forest loss subset from the GFC product following the methodology used by [40]. In this approach, the strata for sampling were based on 'natural forest loss' and 'no loss' classes for both the pre-2000 and post-2000 periods. For each forest loss period, sample pixels were drawn using a stratified random sampling design. Following the "good practices" suggested by [45], in order to balance the area estimates and all accuracies, we used a sampling design slightly away from proportional such that rare strata have a sample size slightly greater than proportional allocation. We used Landsat imagery mosaics for 1988 and 2000 along with composites for 1990 and 1995 for visual assessment of the pre-2000 loss validation samples. Landsat images, where available (Table S2), the minimum annual NDVI, and Google Earth imagery were used, in addition to the 2000 and 2012 Landsat mosaics for an assessment of the 2001-2012 validation samples. Following the visual assessment of all samples, an accuracy assessment of the map and sample-based area estimation of mapped classes was conducted following the method for the land area change estimation described in [46]. Additionally, we followed the same procedure to estimate the forest loss area within the tiger habitat separately 
using only validation samples within the TCL. The accuracy of the plantation map is reported in [38]. The overall accuracy of the plantation map is $86.7 \%$, while the producer's and user's accuracies were $96.8 \%$ and $78.8 \%$, respectively.

Our total natural forest loss and habitat loss area estimates were obtained from the sample-based area estimation for pre-2000 and post-2000. The error-adjusted area for natural forest and habitat loss within plantations was estimated by using the proportion of mapped loss within plantations. The error-adjusted estimates for the annual area of natural forest and habitat loss between 2001 and 2012 were obtained by disaggregating the post-2000 sample-based area estimate into annual time scales using the yearly proportion of post-2000 natural forest and habitat loss. All areas reported in the paper are based on error-adjusted area estimates unless categorically noted as "mapped area" or "mapped loss".

\section{Results}

\subsection{Natural Forest Extent and Change from 1988-2012}

The total natural forest area within Peninsular Malaysia in 1988 was estimated as 7.16 Mha. Roughly, $65 \%$ of the 1988 natural forest area was within the TCL and is considered as tiger habitat for the remaining analysis. The error-adjusted areas for total forest loss and habitat loss, along with their error estimates, are reported in Table 2. Standard errors for pre-2000 and post-2000 sample-based area estimates were obtained following [46], while the total error for the sample-based area estimate was obtained following the method for propagation of error suggested by the Intergovernmental Panel on Climate Change (IPCC) Guidelines [47]. Our map (Figure 3) underestimates the area of loss and the sample-based area estimates (Table 2) are higher than the mapped loss for both periods (579,568 ha for pre-2000 and 565,881 ha for post-2000).

By 2012, the total gross forest loss area in Peninsular Malaysia was estimated to be 1.35 Mha, or $19 \%$ of its 1988 natural forest area (Figure 3, Table 2). The annual rate of loss has increased between the two periods from an average of 49,281 ha year $^{-1}$ pre-2000 to 63,422 ha year ${ }^{-1}$ post-2000 (Figure 4). Using the GFC product, we estimated loss at an annual time step for the post-2000 period. This annual loss has been increasing since 2001 and reached a peak at 122,167 ha in 2012 (Figure 4).

Plantation expansion is responsible for 651,757 ha or $48 \%$ of the total natural forest loss. The mean annual rate of natural forest converted to plantations has increased from 19,970 ha year $^{-1}$ pre-2000 to 34,344 ha year $^{-1}$ post-2000 (Figure 4). The majority of the forest loss converted to plantations (57\% loss within plantations) was due to the large industrial plantation expansion. Recently cleared land constitutes $17 \%$ and $30 \%$ of all pre-2000 and post-2000 forest loss within plantations, respectively. Based on the species information associated with large industrial plantations, we estimate that oil palm dominated plantations constitute about $80 \%$ of the total forest loss (1988-2000) converted to this category, while the proportion of forest loss converted to large rubber plantations has increased from $15 \%$ pre- 2000 to $25 \%$ post- 2000 .

Table 2. Sample-based area (Mha) estimates with 95\% confidence intervals for pre-2000 and post-2000 total natural forest and habitat loss and loss within plantations by 2014 .

\begin{tabular}{ccccc}
\hline Study Period & Total Loss & $\begin{array}{c}\text { Total Loss } \\
\text { within Plantations }\end{array}$ & Habitat Loss & $\begin{array}{c}\text { Habitat Loss } \\
\text { within Plantations }\end{array}$ \\
\hline Pre-2000 & $0.59 \pm 0.11$ & $0.24 \pm 0.05$ & $0.42 \pm 0.11$ & $0.15 \pm 0.04$ \\
Post-2000 & $0.76 \pm 0.13$ & $0.41 \pm 0.07$ & $0.41 \pm 0.10$ & $0.23 \pm 0.06$ \\
Total & $1.35 \pm 0.17$ & $0.65 \pm 0.08$ & $0.83 \pm 0.15$ & $0.38 \pm 0.07$ \\
\hline
\end{tabular}




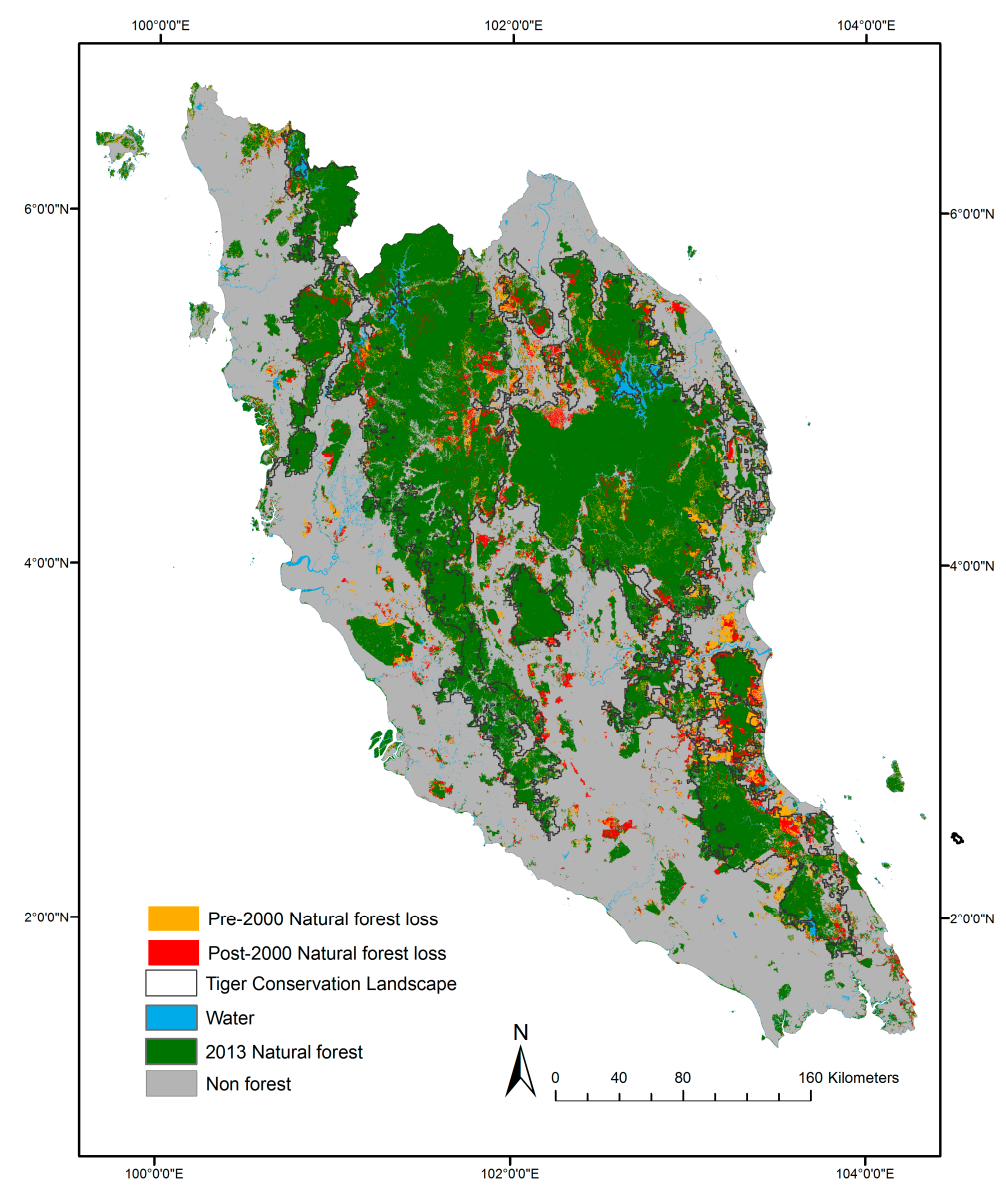

Figure 3. Mapped natural forest remaining in 2013, tiger conservation landscape (TCL), and natural forest loss between 1988-2000 (pre-2000) and 2001-2012 (post-2000).

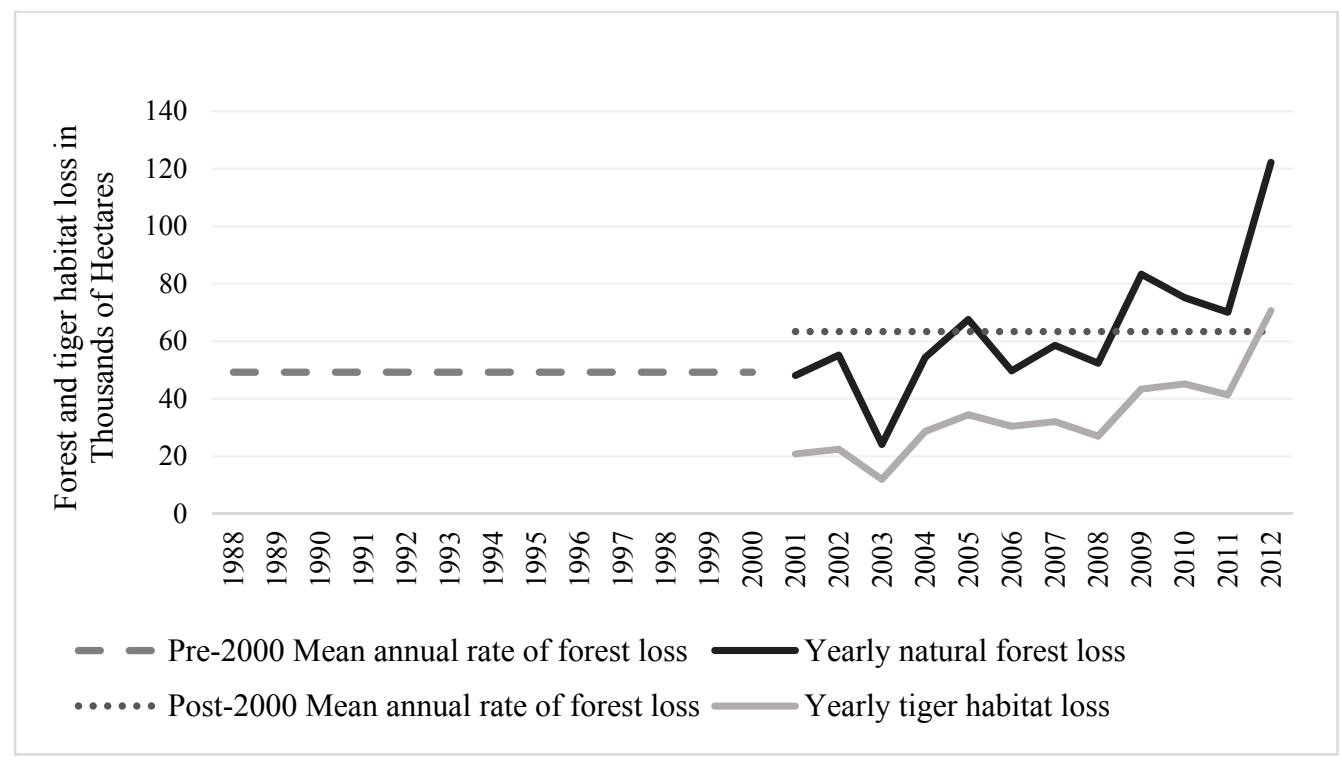

Figure 4. Sample-based area (thousand ha) estimates for yearly natural forest and habitat loss and annual rates of total natural forest loss for pre-2000 and post-2000 periods. Yearly losses are depicted as solid lines, while mean annual rates of loss for the pre-2000 and post-2000 periods are average rates of loss for the respective periods, depicted as constant dashed lines. 


\subsection{Tiger Habitat Loss and Change from 1988-2012}

A total of 831,571 hectares of tiger habitat ( $18 \%$ of 1988 habitat area) have been lost over the entire study period. The average annual habitat loss pre-2000 and post-2000 has remained nearly the same (34,060 ha and 35,237 ha, respectively). However, the annual habitat area lost has been increasing from 2001 to 2012, with an estimated 70,692 ha lost in the year 2012 (Figure 4).

Approximately $46 \%$ of the total habitat loss has been converted to plantations, adding 381,808 ha to Peninsular Malaysia's land under plantations by 2014. The rate of habitat conversion to plantations

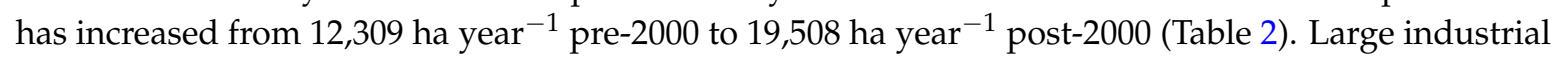
plantations constitute the largest fraction (61\% of pre-2000 loss and $49 \%$ of post-2000 loss) of the converted habitat area, followed by cleared land ( $23 \%$ of pre-2000 loss and $37 \%$ of post-2000 loss), while the remaining converted habitat is within mosaic plantations (Figure 5a). The habitat loss area from more recent years has a greater proportion within the recently cleared plantation class (Figure 5b). Large industrial monoculture plantations established within the tiger habitat are dominated by oil palm; $65 \%$ of all habitat loss converted to large plantations is now under oil palm, while the remaining $(35 \%)$ habitat loss converted to large plantations is under rubber cultivation. However, the proportional area of large industrial plantations under rubber cultivation that has been established from habitat loss has increased between pre-2000 and post-2000 from 29 to $41 \%$.

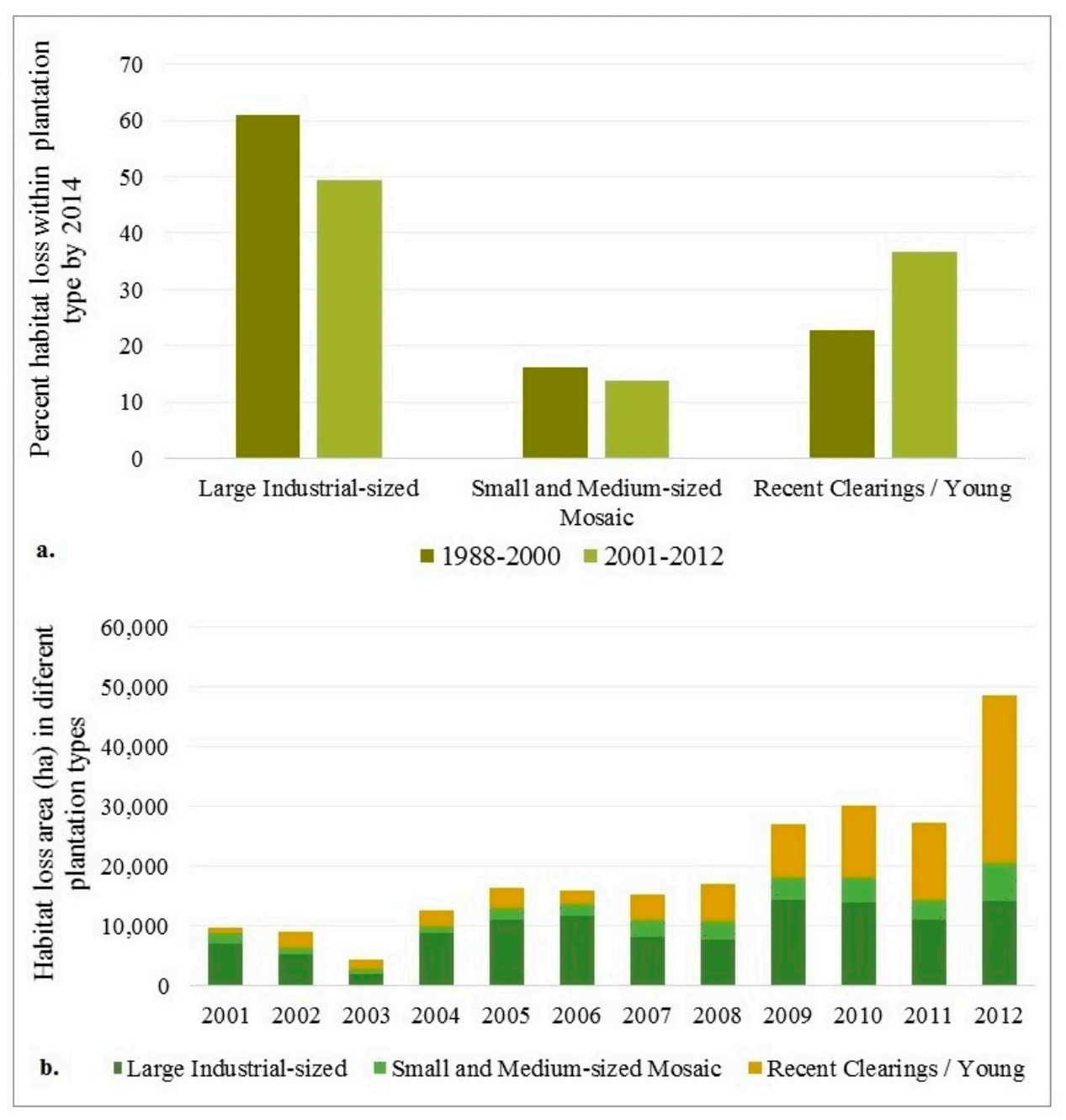

Figure 5. (a) Percent of total tiger habitat loss pre-2000 (1988-2000) and post-2000 (2001-2012) within different plantation types by 2014 (b) Sample-based area of habitat loss between 2001 and 2012 within plantations (in 2014) by plantation type. 


\subsection{Accuracy Assessment of 1988-2000 and 2001-2012 Forest Loss}

We performed separate accuracy assessments for natural forest loss and tiger habitat loss for the 1988-2000 interval mapped in this research and 2001-2012 loss obtained from the GFC product (Table 3). The overall accuracy for both products exceeds 95\%; however, specific user's and producer's accuracies for each class vary. The lowest producer's accuracies are reported for forest loss classes within the TCL (below 60\%). User's accuracies are consistently higher, with the lowest value $(75 \%)$ reported for the forest loss class in the pre-2000 mapping period.

Table 3. Error Matrices for pre-2000 (1988-2000) and post-2000 (2001-2012) natural forest and habitat loss/no loss maps with cell entries depicting the estimated area proportions. $\mathrm{N}$ is the number of total sample points used for the assessment.

\begin{tabular}{ccccccc}
\hline & \multicolumn{5}{c}{ Reference } \\
\cline { 2 - 6 } & Loss & No Loss & Total & User's & Producer's Overall \\
\hline Pre-2000 Forest & $\mathrm{N}=475$ & & & & & \\
\hline Map & & & & & \\
\hline Loss & 0.06 & 0.02 & 0.08 & 0.75 & 0.75 & 0.96 \\
No Loss & 0.02 & 0.9 & 0.92 & 0.98 & 0.98 & \\
Total & 0.08 & 0.92 & 1 & & & \\
\hline Post-2000 Forest & $\mathrm{N}=489$ & & & & & \\
\hline Map & & & & & & \\
\hline Loss & 0.07 & 0.01 & 0.08 & 0.88 & 0.63 & \\
No Loss & 0.04 & 0.88 & 0.92 & 0.96 & 0.99 & \\
Total & 0.12 & 0.88 & 1 & & & \\
\hline Pre-2000 Habitat & $\mathrm{N}=314$ & & & & & \\
\hline Map & & & & & \\
\hline Loss & 0.05 & 0.01 & 0.06 & 0.90 & 0.55 & \\
No Loss & 0.04 & 0.90 & 0.94 & 0.96 & 0.99 & \\
Total & 0.09 & 0.91 & 1.00 & & & \\
\hline Post-2000 Habitat & $\mathrm{N}=358$ & & & & & \\
\hline Map & & & & & \\
\hline Loss & 0.06 & 0.005 & 0.06 & 0.92 & 0.57 & \\
No Loss & 0.04 & 0.90 & 0.94 & 0.96 & 0.99 & \\
Total & 0.096 & 0.904 & 1.00 & & & \\
\hline & & & & & \\
\hline
\end{tabular}

\section{Discussion}

Sample-based area estimates provide a better estimation of loss area than simple map-based estimates [46] and have been used to correct for the underestimation of forest loss [48,49]. Error-adjustment increased the estimated areas of natural forest loss and tiger habitat loss for both pre-2000 and post-2000 periods. User's and producer's accuracies are not distributed uniformly, although the omission error is consistently high for both periods for natural forest and tiger habitat loss.

Based on our total estimated gross natural forest loss of 1.35 Mha, it is evident that deforestation continues to be a problem for Peninsular Malaysia's forest. Our estimated forest loss area from 2000-2010 of 0.49 Mha is higher compared to the 0.44 Mha value reported by [23]. This difference can be attributed to the improved spatial resolution of data used ( $250 \mathrm{~m}$ vs. $30 \mathrm{~m}$ in this study), and the implementation of the sample-based unbiased area estimation method. We observe an acceleration in forest loss from pre-2000 to post-2000, similar to previous reports across the humid tropics and in Asia [25]. Our study adds to a recent study of global tiger habitat [17] and provides a more extensive assessment of habitat loss within Peninsular Malaysia and the contribution of expanding plantations. However, we have only mapped forest loss within habitat and have not assessed the quality of the remaining habitat, which can be further affected by the fragmentation or creation of greater edge and increased access. Furthermore, the estimated conversion of natural forests and habitat to plantations in 
our study is limited by the plantation dataset used. Any undetected or cryptic plantations will result in an underestimation of the forest area converted to plantations over the study period. While any forest conversion to cryptic plantations is a concern for tiger habitat loss, the forest area converted to these plantations is of relatively low importance when compared with forest conversions to large industrial plantations like those of oil palm and rubber.

With $48 \%$ of all the natural forest lost during 1988-2012 converted to plantations by 2014, plantation expansion can be considered a major contributor to forest loss in Peninsular Malaysia. Large industrial plantations constitute more than half of the forest converted to plantations in both study periods. Contrary to claims by the Malaysian palm oil industry [50,51], our results show that oil palm plantations have continued to expand at the expense of natural forest areas. Our analysis shows that approximately 242,000 ha of mapped forest loss between 1988 and 2012 were converted to industrial oil palm plantations by 2014. Additionally, we observe an increased conversion of both forest and habitat loss to plantations post-2000, primarily due to the observed increase of annual loss after 2006, especially within tiger habitat. The proportion of total loss converted to plantations has increased from 40 to $54 \%$ between the two periods, while the proportion of habitat loss converted to plantations has increased from 35 to $57 \%$.

Although the conversion of forest and habitat to oil palm plantations has dominated throughout the study period, the proportion of conversions to large-scale rubber plantations has increased significantly post-2000. Mapped habitat loss converted to rubber plantations has increased by $96 \%$ between pre-2000 and post-2000, while conversions to oil palm plantations have only increased by about $14 \%$, suggesting that rubber cultivation could be a developing threat for the forests and tiger habitat. Other reports also indicate substantial increases in the forest reserve area converted to rubber plantations between 2005 and 2012 [3]. Latex-timber clones, rubber trees that can be used for both rubber and timber, are being propagated across the landscape as a means to expand timber plantations [15]. Policies that allow for selectively logged forests under state jurisdiction to be converted to rubber tree plantations [15] and aggressive plantation schemes by the government [3] continue to endanger Malaysia's forests and tiger habitat.

The observed increase in habitat loss under the cleared plantation class could probably be explained by delays in plantation establishment after forest clearing and that recently established plantations could look very similar to land cleared for other land-uses [52]. It is important to note that our analysis focuses on forest loss area that is under plantation in the year 2014 and other intermediary land uses could exist before plantation establishment. Forest conversion has been shown to follow initial logging disturbance in Indonesia [27]. In Peninsular Malaysia, oil palm plantations are usually established on degraded, previously logged forest or other existing plantations [31,33]. Moreover, about $85 \%$ of the Malaysian tiger population inhabits forest reserves that have been predominantly assigned for selective logging [53]. It is essential that the role of logging in deforestation and habitat loss in the region be further investigated.

\section{Conclusions}

The Malayan tiger continues to be threatened by habitat loss and fragmentation despite Malaysia's relatively large area under forest cover [54]. Our study maps the natural forest for Peninsular Malaysia for circa 1988 and the forest loss between 1988 and 2000, and aggregates our forest loss with the GFC global forest loss product to produce a consistent forest loss dataset from 1988 to 2012 for the region. We find that natural forest loss continues within Peninsular Malaysia, specifically within its tiger habitat. The conversion of forests to plantations within the region is responsible for about half of all the deforestation. Furthermore, we find that the contribution of plantations to the total area of natural forest loss has increased from pre-2000 to post-2000. Large industrial plantations and recently cleared land are the major contributors of land-use conversion. While large industrial plantations continue to be dominated by oil palm, conversion to rubber plantations has been on the rise. In this work, we have quantified the total loss of habitat but have not assessed more subtle changes in habitat quality that 
result from natural forest conversion. Our map product enables studying the spatial distribution and patterns of natural forest loss within Peninsular Malaysia and its tiger habitat.

Supplementary Materials: The following are available online at www.mdpi.com/2072-4292/9/7/747/s1, Table S1: Image numbers per year and per Landsat sensor used for mapping; Table S2: Landsat images used for validation.

Author Contributions: V.S., P.P., and T.L. conceived and designed the experiments; V.S. performed the experiments; V.S., P.P., and T.L. analyzed the data; P.P. and N.H. contributed reagents/materials/analysis tools; V.S., P.P., N.H., and T.L. wrote the paper.

Conflicts of Interest: The authors declare no conflict of interest.

\section{References}

1. Convention on Biodiversity Diversity (CBD). Malaysia: Country Profile. Available online: https://www.cbd. int/countries/profile/default.shtml?country=my\#facts (accessed on 10 December 2015).

2. Myers, N.; Mittermeier, R.A.; Mittermeier, C.G.; Da Fonseca, G.A.; Kent, J. Biodiversity hotspots for conservation priorities. Nature 2000, 403, 853-858. [CrossRef] [PubMed]

3. Kawanishi, K. Panthera tigris ssp. jacksoni. The IUCN Red List of Threatened Species 2015: E.T136893A50665029. 2015. Available online: http://dx.doi.org/10.2305/IUCN.UK.2015-2.RLTS. T136893A50665029.en (accessed on 10 October 2016).

4. Seidensticker, J. Saving wild tigers: A case study in biodiversity loss and challenges to be met for recovery beyond 2010. Integr. Zool. 2010, 5, 285-299. [CrossRef] [PubMed]

5. Gibbs, H.K.; Ruesch, A.S.; Achard, F.; Clayton, M.K.; Holmgren, P.; Ramankutty, N.; Foley, J.A. Tropical forests were the primary sources of new agricultural land in the 1980s and 1990s. Proc. Natl. Acad. Sci. USA 2010, 107, 16732-16737. [CrossRef] [PubMed]

6. Sodhi, S.N.; Posa, R.C.M.; Lee, M.T.; Bickford, D.; Koh, P.L.; Brook, W.B. The state and conservation of Southeast Asian biodiversity. Biodivers. Conserv. 2010, 19, 317-328. [CrossRef]

7. Kummer, D.M.; Turner, B.L. The human causes of deforestation in Southeast Asia. Bioscience 1994, 44, 323-328. [CrossRef]

8. Abdullah, S.A.; Nakagoshi, N. Forest fragmentation and its correlation to human land use change in the state of Selangor, peninsular Malaysia. For. Ecol. Manag. 2007, 241, 39-48. [CrossRef]

9. Abdullah, S.A.; Hezri, A.A. From forest landscape to agricultural landscape in the developing tropical country of Malaysia: Pattern, process, and their significance on policy. Environ. Manag. 2008, 42, 907-917. [CrossRef] [PubMed]

10. Koh, L.P.; Wilcove, D.S. Is oil palm agriculture really destroying tropical biodiversity? Conserv. Lett. 2008, 1, 60-64. [CrossRef]

11. Food and Agriculture Organization of the United Nations (FAO). Case Study of Tropical Forest Plantations in Malaysia by D.B.A Krishnapillay; Forest Plantations Working Paper 23; FAO: Rome, Italy, 2002; unpublished; Available online: http://www.fao.org/documents/card/en/c/8ac53512-c384-5b5a-baf4-f6d137e3a421/ (accessed on 11 July 2017).

12. Byerlee, D. The Fall and Rise Again of Plantations in Tropical Asia: History Repeated? Land 2014, 3, 574-597. [CrossRef]

13. Fitzherbert, E.B.; Struebig, M.J.; Morel, A.; Danielsen, F.; Brühl, C.A.; Donald, P.F.; Phalan, B. How will oil palm expansion affect biodiversity? Trends Ecol. Evol. 2008, 23, 538-545. [CrossRef] [PubMed]

14. Brookfield, H.; Byron, Y. Deforestation and timber extraction in Borneo and the Malay Peninsula: The record since 1965. Glob. Environ. Chang. 1990, 1, 42-56. [CrossRef]

15. Clements, R.; Rayan, D.M.; Zafir, A.W.A.; Venkataraman, A.; Alfred, R.; Payne, J.; Ambu, L.; Sharma, D.S.K. Trio under threat: Can we secure the future of rhinos, elephants and tigers in Malaysia? Biodivers. Conserv. 2010, 19, 1115-1136. [CrossRef]

16. Kawanishi, K.; Yatim, S.H.; Abu Hashim, A.K.; Topani, R. Distribution and potential population size of the tiger in Peninsular Malaysia. J. Wildl. Park. 2003, 21, 29-50.

17. Joshi, A.R.; Dinerstein, E.; Wikramanayake, E.; Anderson, M.L.; Olson, D.; Jones, B.S.; Seidensticker, J.; Lumpkin, S.; Hansen, M.C.; Sizer, N.C.; et al. Tracking changes and preventing loss in critical tiger habitat. Sci. Adv. 2016, 2, e1501675. [CrossRef] [PubMed] 
18. World Bank (Washington, DC, USA). Global Tiger Recovery Program (2010-2022). Available online: http:// documents.worldbank.org/curated/en/874191468331048098/Global-tiger-recovery-program-2010-2022 (accessed on 27 June 2017).

19. Global Tiger Recovery Program (GTRP). Global Tiger Recovery Program Volume 2. Draft 31 July 2010. Washington, DC, USA, 2010. Available online: http://admin.indiaenvironmentportal.org.in/files/GTRPVolume-2-July-31.pdf (accessed on 27 June 2017).

20. Department of Wildlife and National Parks Peninsular Malaysia (DWNP). National Tiger Action Plan for Malaysia 2008-2020; DWNP: Kuala Lumpur, Malaysia, 2008.

21. Hansen, M.C.; Stehman, S.V.; Potapov, P.V.; Loveland, T.R.; Townshend, J.R.; DeFries, R.S.; Pittman, K.W.; Arunarwati, B.; Stolle, F.; Steininger, M.K.; et al. Humid tropical forest clearing from 2000 to 2005 quantified by using multitemporal and multiresolution remotely sensed data. Proc. Natl. Acad. Sci. USA 2008, 105, 9439-9444. [CrossRef] [PubMed]

22. Hansen, M.C.; Stehman, S.V.; Potapov, P.V. Quantification of global gross forest cover loss. Proc. Natl. Acad. Sci. USA 2010, 107, 8650-8655. [CrossRef] [PubMed]

23. Miettinen, J.; Shi, C.; Liew, S.C. Deforestation rates in insular Southeast Asia between 2000 and 2010. Glob. Chang. Biol. 2011, 17, 2261-2270. [CrossRef]

24. Hansen, M.C.; Potapov, P.V.; Moore, R.; Hancher, M.; Turubanova, S.A.; Tyukavina, A.; Thau, D.; Stehman, S.V.; Goetz, S.J.; Loveland, T.R.; et al. High-resolution global maps of 21st-century forest cover change. Science 2013, 342, 850-853. [CrossRef] [PubMed]

25. Kim, D.; Sexton, J.O.; Townshend, J.R. Accelerated deforestation in the humid tropics from the 1990s to the 2000s. Geophys. Res. Lett. 2015, 42, 3495-3501. [CrossRef] [PubMed]

26. Cohen, W.B.; Goward, S.N. Landsat's role in ecological applications of remote sensing. Bioscience 2004, 54, 535-545. [CrossRef]

27. Margono, B.A.; Potapov, P.V.; Turubanova, S.; Stolle, F.; Hansen, M.C. Primary forest cover loss in Indonesia over 2000-2012. Nat. Clim. Chang. 2014, 4, 730-735. [CrossRef]

28. Srinivas, A.; Koh, L.P. Oil palm expansion drives avifaunal decline in the Pucallpa region of Peruvian Amazonia. Glob. Ecol. Conserv. 2016, 7, 183-200. [CrossRef]

29. Peh, K.S.H.; Sodhi, N.S.; De Jong, J.; Sekercioglu, C.H.; Yap, C.A.M.; Lim, S.L.H. Conservation value of degraded habitats for forest birds in southern Peninsular Malaysia. Divers. Distrib. 2006, 12, 572-581. [CrossRef]

30. Maddox, T. The Conservation of Tigers and Other Wildlife in Oil Palm Plantations: Jambi Province, Sumatra, Indonesia; Zoological Society of London (ZSL): London, UK, 2007.

31. Wicke, S.; Sikkema, R.; Dornburg, V.; Faaij, A. Exploring land use changes and the role of palm oil production in Indonesia and Malaysia. Land Use Policy 2011, 28, 193-206. [CrossRef]

32. McMorrow, J.; Talip, M.A. Decline of forest area in Sabah, Malaysia: Relationship to state policies, land code and land capability. Glob. Environ. Chang. 2001, 11, 217-230. [CrossRef]

33. Gunarso, P.; Hartoyo, M.; Agus, F.; Killeen, T. Oil Palm and Land Use Change in Indonesia, Malaysia and Papua New Guinea; Reports from the Technical Panels of the 2nd Greenhouse Gas Working Group of the Roundtable on Sustainable Palm Oil (RSPO); RSPO: Kuala Lumpur, Malaysia, 2013; pp. 29-64. Available online: http:/ / www.rspo.org/key-documents/supplementary-materials (accessed on 20 June 2016).

34. Food and Agriculture Organization of the United Nations (FAO). Countries: Geography Malaysia. 2012. Available online: http:/ / www.fao.org/forestry/country/18310/en/mys/ (accessed on 22 June 2017).

35. Forestry Department of Peninsular Malaysia (FDPM). Forest Types. 2016. Available online: https:// www.forestry.gov.my/index.php/en/2016-06-07-02-31-39/2016-06-07-02-35-17/forest-type (accessed on 22 June 2017).

36. Sanderson, E.; Forrest, J.; Loucks, C.; Ginsberg, J.; Dinerstein, E.; Seidensticker, J.; Leimgruber, P.; Songer, M.; Heydlauff, A.; O'Brien, T.; et al. Setting Priorities for the Conservation and Recovery of Wild Tigers: 2005-2015. The Technical Assessment; World Wildlife Fund: Washington, DC, USA; Wildlife Conservation Society: New York, NY, USA; Smithsonian, and National Fish and Wildlife Foundation: Washington, DC, USA, 2006.

37. UNEP-WCMC and IUCN. Protected Planet: The World Database on Protected Areas (WDPA). UNEP-WCMC: Cambridge, UK, 2016. Available online: www.protectedplanet.net (accessed on 10 February 2016). 
38. Petersen, R.; Aksenov, D.; Goldman, E.; Sargent, S.; Harris, N.; Manisha, A.; Esipova, E.; Shevade, V.; Loboda, T. Mapping Tree Plantations with Multispectral Imagery: Preliminary Results for Seven Tropical Countries; Technical Note; World Resources Institute: Washington, DC, USA, 2016. Available online: http:/ /www.wri. org/publication/mapping-tree-plantations (accessed on 23 September 2016).

39. Potapov, P.V.; Turubanova, S.A.; Hansen, M.C.; Adusei, B.; Broich, M.; Altstatt, A.; Mane, L.; Justice, C.O. Quantifying forest cover loss in Democratic Republic of the Congo. 2000-2010, with Landsat ETM+ data. Remote Sens. Environ. 2012, 122, 106-116. [CrossRef]

40. Potapov, P.V.; Turubanova, S.A.; Tyukavina, A.; Krylov, A.M.; McCarty, J.L.; Radeloff, V.C.; Hansen, M.C. Eastern Europe's forest cover dynamics from 1985 to 2012 quantified from the full Landsat archive. Remote Sens. Environ. 2015, 159, 28-43. [CrossRef]

41. Tucker, C.J. Red and photographic infrared linear combinations for monitoring vegetation. Remote Sens. Environ. 1979, 8, 127-150. [CrossRef]

42. Xiao, X.; Zhang, Q.; Braswell, B.; Urbanski, S.; Boles, S.; Wofsy, S.C.; Moore, B.; Ojima, D. Modeling gross primary production of a deciduous broadleaf forest using satellite images and climate data. Remote Sens. Environ. 2004, 91, 256-270. [CrossRef]

43. Breiman, L. Bagging predictors. Mach. Learn. 1996, 24, 123-140. [CrossRef]

44. Giree, N.; Stehman, S.V.; Potapov, P.; Hansen, M.C. A sample-based forest monitoring strategy using Landsat, AVHRR and MODIS data to estimate gross forest cover loss in Malaysia between 1990 and 2005. Remote Sens. 2013, 5, 1842-1855. [CrossRef]

45. Olofsson, P.; Foody, G.M.; Herold, M.; Stehman, S.V.; Woodcock, C.E.; Wulder, M.A. Good practices for estimating area and assessing accuracy of land change. Remote Sens. Environ. 2014, 148, 42-57. [CrossRef]

46. Olofsson, P.; Foody, G.M.; Stehman, S.V.; Woodcock, C.E. Making better use of accuracy data in land change studies: Estimating accuracy and area and quantifying uncertainty using stratified estimation. Remote Sens. Environ. 2013, 129, 122-131. [CrossRef]

47. Intergovernmental Panel on Climate Change (IPCC). 2006 IPCC Guidelines for National Greenhouse Gas Inventories, Prepared by the National Greenhouse Gas Inventories Programme; Eggleston, H.S., Buendia, L., Miwa, K., Ngara, T., Tanabe, K., Eds.; Institute for Global Environmental Strategies: Hayama, Japan, 2006.

48. Tyukavina, A.; Stehman, S.V.; Potapov, P.V.; Turubanova, S.A.; Baccini, A.; Goetz, S.J.; Laporte, N.T.; Houghton, R.A.; Hansen, M.C. National-scale estimation of gross forest aboveground carbon loss: A case study of the Democratic Republic of the Congo. Environ. Res. Lett. 2013, 8, 044039. [CrossRef]

49. Potapov, P.V.; Dempewolf, J.; Talero, Y.; Hansen, M.C.; Stehman, S.V.; Vargas, C.; Rojas, E.J.; Castillo, D.; Mendoza, E.; Calderón, A.; et al. National satellite-based humid tropical forest change assessment in Peru in support of REDD+ implementation. Environ. Res. Lett. 2014, 9, 124012. [CrossRef]

50. Sheil, D.; Casson, A.; Meijaard, E.; van Nordwijk, M.; Gaskell, J.; Sunderland-Groves, J.; Wertz, K.; Kanninen, M. The Impacts and Opportunities of Oil Palm in Southeast Asia: What Do We Know and What Do We Need to Know? Occasional Paper No. 51; Center for International Forestry Research (CIFOR): Bogor, Indonesia, 2009.

51. Gaveau, D.L.; Sheil, D.; Husnayaen, M.A.S.; Arjasakusuma, S.; Ancrenaz, M.; Pacheco, P.; Meijaard, E. Rapid conversions and avoided deforestation: Examining four decades of industrial plantation expansion in Borneo. Sci. Rep. 2016, 6, 32017. [CrossRef] [PubMed]

52. Koh, L.P.; Miettinen, J.; Liew, S.C.; Ghazoul, J. Remotely sensed evidence of tropical peatland conversion to oil palm. Proc. Natl. Acad. Sci. USA 2011, 108, 5127-5132. [CrossRef] [PubMed]

53. Rayan, D.M.; Linkie, M. Conserving tigers in Malaysia: A science-driven approach for eliciting conservation policy change. Biol. Conserv. 2015, 184, 18-26. [CrossRef]

54. Rayan, D.M.; Mohamad, S.W. The importance of selectively logged forests for tiger Panthera tigris conservation: A population density estimate in Peninsular Malaysia. Oryx 2009, 43, 48-51. [CrossRef]

(C) 2017 by the authors. Licensee MDPI, Basel, Switzerland. This article is an open access article distributed under the terms and conditions of the Creative Commons Attribution (CC BY) license (http:/ / creativecommons.org/licenses/by/4.0/). 